\title{
Automated Calculation of Optimal Cutting Conditions for Low-Temperature Steel
}

\author{
V. A. Rogov, E. V. Fomin, and A. V. Fomin \\ Russian Peoples' Friendship University, Moscow \\ Arkhangelsk State Technical University, Arkhangelsk \\ SEVMAShVTUZ Branch, St Petersburg State Marine-Technology University, Severodvinsk
}

DOI: $10.3103 / \mathrm{S} 1068798 \mathrm{X} 10080228$

The effectiveness of production processes depends largely on the selected operating conditions. Therefore, choosing the best cutting conditions offers scope for improving the overall profitability of manufacturing production, without additional labor or material outlays.

Improving the profitability of a manufacturing enterprise must begin with consideration of the machining operations and the selection of the best operating conditions, which ultimately determine the productivity and production costs.

Therefore, there is a clear need to develop computer software for optimization of the cutting conditions at the design stage and corresponding maximization of manufacturing efficiency, without additional labor or material outlays

Accordingly, the REZNET system has been developed for the identification of optimal cutting conditions in the design of a technological process on the basis of experimental data and multifactorial mathematical models. A block diagram of the REZMET program is shown in the figure.

This system is intended to produce recommendations that consist of independent sections for the basic types of machining (drilling, thread cutting by taps, end and face milling) for 10 ГНБ low-temperature steel blanks.

In accordance with the block diagram, the system operates as follows.

(1) Selection of the type of machining (drilling, thread cutting by taps, end and face milling).

(2) Specification of the initial machining parameters: dimensions of the machined surface (hole diameter and depth; thread size and length; milling width and depth; supply); the machining conditions (tool material; type and state of blank; lubricant and coolant fluid); and the required tool life.

(3) Determination of correction coefficients on the basis of the selected machining parameters.

(4) Compilation of tables of optimal cutting conditions to ensure the required tool life, with recommendations regarding the machining conditions.
(5) Selection of the tool required for optimal machining.

The results obtained from the REZMET system are displayed in tabular form on the screen. This software is written in the Delphi 7 environment and operates in the Windows operating system.

The REZMET system also includes detailed explanations and notes that significantly facilitate its use.

Thus, the REZMET system permits the determination of optimal cutting conditions for low-temperature steel in the design of a technological process; specifically, recommendations are made regarding drilling, thread cutting by taps, and end and face milling. These recommendations improve production quality.

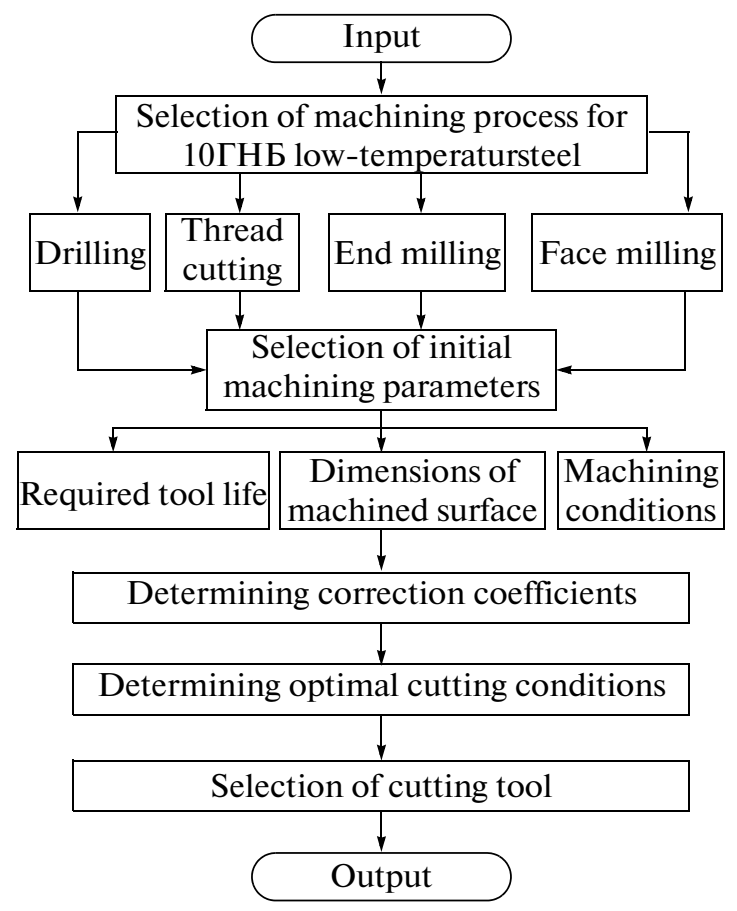

REZMET program. 